\title{
Single- and Multiple-Dose Pharmacokinetics of a Novel Tetramethylpyrazine Reservoir-Type Transdermal Patch versus Tetramethylpyrazine Phosphate Oral Tablets in Healthy Normal Volunteers, and in Vitro/in Vivo Correlation
}

\author{
Teng Shen, ${ }^{*, a}$ Huinan $\mathrm{Xu},{ }^{a}$ Weiyu Weng, ${ }^{b}$ and Jianfang Zhang ${ }^{a}$ \\ ${ }^{a}$ Key Laboratory of Smart Drug Delivery, Ministry of Education \& PLA, Department of Pharmaceutics, School \\ of Pharmacy, Fudan University; Shanghai 201203, China: and ${ }^{b}$ School of Pharmacy, East China University of \\ Science and Technology; Shanghai 200237, China. \\ Received October 18, 2012; accepted March 12, 2013; advance publication released online March 19, 2013
}

\begin{abstract}
A novel reservoir-type transdermal system of 2,3,5,6-tetramethylpyrazine (TMP) was developed containing eucalyptus oil as a penetration enhancer. The single and multiple-dose pharmacokinetic profiles of TMP administrated by TMP transdermal patch were characterized in healthy volunteers using an in vivo, randomized, open-label, two-way crossover design. 2,3,5,6-Tetramethylpyrazine phosphate (TMPP) oral tablets were chosen as reference. Following single/multiple oral administration of 200/100 mg TMPP tablets, a TMP $C_{\max }$ of $1284 / 613.5 \mathrm{ng} / \mathrm{mL}$ was observed within $0.75 \mathrm{~h}$. Single/multiple applications of the TMP patch yielded mean $C_{\max }$ of $309 / 325 \mathrm{ng} / \mathrm{mL}$ at a median $T_{\max }$ of $5 / 4 \mathrm{~h}$, with steady state achieved at second application. The mean $C_{\min }$ of the patch was $131 \pm 30.38 \mathrm{ng} / \mathrm{mL}$, contrasting to nearly zero for the tablet. Multiple applications of patch produced an accumulative effect over single application. At steady state $250 \mathrm{mg} / 20 \mathrm{~cm}^{2}$ TMP patch given daily provided comparable exposure to $100 \mathrm{mg}$ TMPP tablets three times daily (3753.91 versus $3563.67 \mathrm{ng} \cdot \mathrm{h} / \mathrm{mL}$ ). TMP tablets and patch yielded similar steady-state plasma concentrations: $C_{\mathrm{av}}$ $(148.48 \pm 51.27,156.41 \pm 40.31 \mathrm{ng} / \mathrm{mL})$. The results demonstrated that TMP patch can achieve a therapeutic effect that is comparable to oral administration, exhibited prolonged and sustained plasma levels, fewer drug fluctuations, lower adverse effects, more convenience, and improved patient compliance. In-vitro permeation through human skin demonstrated zero-order kinetics with the flux of $364 \mu \mathrm{g} / \mathrm{cm}^{2} / \mathrm{h}$. The predicted $C_{\text {av }}$ $(163.9 \mathrm{ng} / \mathrm{mL})$ was in agreement with the observed $C_{\text {av }}(156.4 \mathrm{ng} / \mathrm{mL})$.
\end{abstract}

Key words tetramethylpyrazine; patch; pharmacokinetics; multiple-dose; transdermal; human skin

2,3,5,6-Tetramethylpyrazine (TMP, structure shown in Fig. 1) is a biologically active compound originally isolated in 1957 from the traditional medicine herb Ligusticum wallichii Franchat (Chuan Xiong). TMP can cross the blood-brain barrier efficiently, ${ }^{1,2)}$ increase cerebral blood flow in an ischemic attack, ${ }^{3)}$ inhibit platelet aggregation in vitro, ${ }^{4,5)}$ and improve blood viscosity. ${ }^{6}$ TMP has been synthesized and used widely in China for the treatment of ischemic cardiovascular and cerebrovascular disease. ${ }^{7)}$

Oral preparations available for TMP include tablets, capsules and pills, which should be taken three times daily. Following oral administration, plasma TMP levels rise sharply to $C_{\max }$ within $1.5 \mathrm{~h}$; it is eliminated quickly with a biological half-life of $0.8-2.8 \mathrm{~h}^{8-10)}$ TMP undergoes high first-pass metabolism with an oral bioavailability of $10-30 \%$ in humans ${ }^{9}$ and $40 \%$ in dogs. ${ }^{11)}$ Because of this, it has been necessary to develop a controlled release system for TMP. Fortunately, TMP's physiochemical properties, such as low molecular weight (136.2), adequate solubility $(11 \mathrm{mg} / \mathrm{mL})$ and lipophilicity $\left(k_{\text {oct-water }}=2.3\right)$, and low melting point $\left(76-78^{\circ} \mathrm{C}\right)$, make it a suitable candidate for transdermal delivery. ${ }^{12)}$ Transdermal delivery systems (TDS) offer many advantages over conventional oral administration, including smooth and continuous drug delivery, lower fluctuations of drug concentration in plasma and steadier systemic drug levels. Also, TDS can often be applied once daily, potentially improving convenience and treatment compliance. ${ }^{13)}$

Various TDS for TMP have been fabricated, such as micro-

The authors declare no conflict of interest. emulsion, ${ }^{14)}$ ethosome patch, ${ }^{15,16)}$ matrix-type, ${ }^{17)}$ and reservoirtype transdermal systems. ${ }^{12,18)}$ However, none of these have been confirmed to deliver a therapeutic dose through human skin or have reached clinical studies. We have developed a novel reservoir-type TDS of TMP sandwiched Carbopol gel, between an impermeable backing layer and a controlling-release membrane with silicone sensitive adhesive. Of note, the reservoir-type TMP TDS contains eucalyptus oil as a penetration enhancer, which can greatly enhance the permeation flux sufficiently enough to delivery drugs through human skin. The TMP TDS patch gained clinical trial approval from the State Food and Drug Administration in China (SFDA).

The current study was conducted during the TMP patch development program to characterize the single- and multipledose pharmacokinetic (PK) profiles of TMP administered by TMP patch, compared with immediate-release oral tablets in healthy Chinese volunteers. The pharmacokinetic characteristics of TMP by oral and intravenous administration in human have been reported, ${ }^{8-10,19)}$ but up to this time no reports about the pharmacokinetics of TMP patch in human have been found. Furthermore, in the current study the in vitro permeation of TMP across human skin was determined and the in vitro/in vivo correlation (IVIVC) was established, as per the study's intended goals.<smiles>Cc1nc(C)c(C)nc1C</smiles>

Fig. 1. The Chemical Structure of TMP 


\section{MATERIALS AND METHODS}

Materials TMP, purity $99.8 \%$, TMPP, purity $99.5 \%$, and TMPP tablets (containing $50 \mathrm{mg}$ TMPP equivalent to $27 \mathrm{mg}$ TMP free base per tablet) were purchased from Beijing Yan Jing Pharmaceutical Factory (Beijing, China). Carbamazepine (purity 99.5\%) was obtained from Shanghai Institute for Drug and Food Control (Shanghai, China). Eucalyptus oil (Shanghai Zhonghua Pharmaceutical Co., Ltd.), CoTran ${ }^{\mathrm{TM}}$ 9728, Scotchpak $^{\mathrm{TM}} 1022$ and Scotchpak ${ }^{\mathrm{TM}} 9732$ were donated by 3M China Ltd. Silicone Pressure Sensitive Adhesive (Dow Corning Shanghai Co., Ltd.), Carbopol 934P (Noveon Shanghai Specialty Polymers Co., Ltd.), Methanol (HPLC grade) and double distilled water were used. All other chemicals used were of analytical grade.

Fabrication of Reservoir-Type TDS A reservoir-type TDS patch of TMP was fabricated by sandwiching the reservoir gel between a drug-impermeable backing laminate and ethylene-vinyl acetate (EVA) copolymer membrane coated with a pressure sensitive adhesive. First, the reservoir gel was fabricated. Carbopol 934P was added to glycerin-water $(1: 1$, $\mathrm{w} / \mathrm{w})$ solution and was kept overnight to allow for complete swelling of the polymer. TMPP was added into $4 \mathrm{M}$ sodium hydroxide solution while stirring and the final $\mathrm{pH}$ was adjusted to 7-8 to prepare the TMP in situ. Then the drug was added slowly into the prepared Carbopol solution while stirring until a gel was formed. Eucalyptus oil and Tween 80 were premixed with ethanol and then were added to the gel and mixed well before use. Second, the silicone adhesive solution was coated onto the fluoropolymer release linear $(3 \mathrm{M}$, Scotchpak ${ }^{\mathrm{TM}}$ 1022) and was allowed to dry completely. Next, the EVA membrane with VA content of $28 \%$ and a thickness of $51 \mu \mathrm{m}\left(3 \mathrm{M}\right.$, CoTran ${ }^{\mathrm{TM}}$ 9728) was pressed over the adhesive layer; thus the composite three layer system was prepared. Finally, the reservoir gel (1.6g) was injected (using a syringe) onto the membrane surface of the composite laminate, and the polyester backing layer with EVA heat-sealable layer (3M, Scotchpak ${ }^{\mathrm{TM}}$ 9732) was used to cover the gel. The two layers were then heat-sealed using a mold preheated to $80^{\circ} \mathrm{C}$ and cut to the appropriate size $\left(20 \mathrm{~cm}^{2}\right.$, containing $\left.250 \mathrm{mg} \mathrm{TMP}\right)$. The TDS patch was kept in a sealed aluminum pouch to minimize the loss of solvent.

In Vitro Permeability Studies across Human Skin Excised human skin from the chest region of a female cadaver aged 40 years taken within $24 \mathrm{~h}$ post-mortem was obtained from Zhongshan Hospital Fudan University. The samples were dermatomized immediately upon arrival to a thickness of approximately $200 \mu \mathrm{m}$. The TDS patch was pressed over the epidermal surface of the human skin and was then mounted onto modified Kershary-Chien diffusion cells. ${ }^{20,21)}$ The receptor compartment contained $15.0 \mathrm{~mL}$ of water bathed at $37 \pm 0.5^{\circ} \mathrm{C}$; the effective diffusion surface was $3.14 \mathrm{~cm}^{2}$. At predetermined times $(1,3,5,7,9,12,24 \mathrm{~h}), 5 \mathrm{~mL}$ samples were withdrawn from the receiver compartment and replaced with an equivalent volume of water to maintain sink conditions.

The concentrations of TMP in receptor medium were then determined using a previously described HPLC method. ${ }^{22)} \mathrm{Cu}$ mulative corrections were made to determine the total amount of TMP permeated at each time interval. Steady-state flux $\left(J_{\mathrm{ss}}\right)$ of TMP $\left(\mathrm{mg} / \mathrm{cm}^{2} / \mathrm{h}\right)$ were determined as the slope of the cumulative amount of drug permeated per $\mathrm{cm}^{2} v s$. time plot using linear regression analysis.

\section{Single and Multiple-Dose Pharmacokinetics Study}

Subjects Twenty healthy, male subjects were enrolled in the single and multiple-dose pharmacokinetics studies. The mean age of the subjects was 23 years $($ S.D. $=0.65)$, the mean height was $170.8 \mathrm{~cm}$ (S.D.=4.3) and the mean weight was $65.4 \mathrm{~kg}$ (S.D.=5.5). Inclusion criteria consisted of the following: shown to be generally in good health according to medical history, physical examination by a physician, and routine laboratory analysis (hematology and urinalysis). None of the volunteers were on drug treatments one week prior to participation in the study. Smoking was not allowed while subjects were housed in the residential unit. Alcohol, caffeine, and xanthine-containing beverages were restricted during the confinement period of the study. Informed consent was obtained from the subjects after explaining the nature and purpose of the study. The protocol of the study followed the tenets of the Declaration of Helsinki and was approved by Ethics Committee of Shanghai Zhong Shan Hospital National Unit of Clinical Study of Drugs. The volunteers had the freedom to withdraw from the study at their discretion.

Protocol for Single Dose Study in Human In the singledose study, a randomized, open-labeled, crossover design was used, with a seven day washout period. After overnight fasting (12h), in the morning subjects were administered either: four TMPP tablets (containing a total of $108 \mathrm{mg}$ TMP free base) together with $200 \mathrm{~mL}$ of water, or one TMP patch (containing a total of $250 \mathrm{mg}$ TMP free base) applied to the chest. The patch remained on the chest for $24 \mathrm{~h}$. No food was permitted until a standardized meal was served $2 \mathrm{~h}$ after dosing. Blood samples $(3 \mathrm{~mL})$ were withdrawn within $30 \mathrm{~min}$ prior to application of the TMP patch and then at $0.5,1,2,3,4,5,6,8,10,12,15$ and $24 \mathrm{~h}$ following patch application. Blood samples were collected within $30 \mathrm{~min}$ prior to tablet administration and then at $0.25,0.5,0.75,1,2,3,4,5,6,8,10,12,15$ and $24 \mathrm{~h}$ after oral TMPP administration. The volunteers had freedom to remove the patch during the study $(24 \mathrm{~h})$, if there was any sign of irritation at the application site. After a 7-d period, the studies were repeated in the same manner to complete the crossover design.

Protocol for Multiple Doses Study in Human In the multiple doses study, a randomized, open-labeled, crossover design was used, with a $14-d$ washout period. During tablet treatment, subjects were administered two tablets $(100 \mathrm{mg}$ TMPP, containing a total of $54 \mathrm{mg}$ TMP free base) three times daily at 7:00 a.m., 3:00 p.m. and 11:00 p.m. every day from day 1 to day 5. During patch treatment, one patch (containing $250 \mathrm{mg}$ TMP free base) was applied daily at 7:00 a.m. for five consecutive days. Blood samples were collected before dose administration every morning on day 3 to day 5 , and at specific time intervals on day 5 as described in study 1 . The blood samples were mixed well and were immediately centrifuged at $6000 \mathrm{rpm}$ for $10 \mathrm{~min}$. The separated plasmas were stored at $-20^{\circ} \mathrm{C}$ until analysis by HPLC. After a $14-\mathrm{d}$ period, the studies were repeated in the same manner to complete the crossover design.

Safety Blood pressure and heart rate were measured every $4 \mathrm{~h}$ between 7:00 a.m. and 11:00 p.m. each day. Reports of general adverse events were elicited by questioning subjects before blood sampling. The application sites of the volunteers were also observed for any signs of skin irritation/sensitiza- 
tion at the end of the in vivo evaluation.

Analysis of Plasma Samples Plasma TMP concentrations were determined by a validated solid-phase extraction HPLC method. ${ }^{23)}$ One milliliter aliquots of plasma were mixed with $500 \mu \mathrm{L}$ of $0.1 \%$ concentrated phosphoric acid and $100 \mu \mathrm{L}$ of Carbamazepine (internal standard; IS) solution. The resulting solution was vortexed and centrifuged for exactly $5 \mathrm{~min}$ at $6000 \mathrm{rpm}$. The cartridge was conditioned sequentially by rinsing it with $1 \mathrm{~mL}$ methanol and $1 \mathrm{~mL}$ of $0.1 \%$ concentrated phosphoric acid. The spiked sample was introduced into the cartridge under vacuum. The cartridge was washed with $1 \mathrm{~mL}$ of $0.1 \%$ phosphoric acid. TMP and IS were then subsequently desorbed with $1 \mathrm{~mL}$ of methanol. The eluted solution was evaporated to dryness in a water bath at $45^{\circ} \mathrm{C}$ under nitrogen steam and the residue reconstituted in $200 \mu \mathrm{L}$ of mobile phase. The resulting solutions were carefully vortexed and centrifuged at $6000 \mathrm{rpm}$ for $10 \mathrm{~min}$. A volume of $20 \mu \mathrm{L}$ was subsequently injected for HPLC analysis. The standard curve was linear over a working range of $30-3000 \mathrm{ng} / \mathrm{mL}$ and gave an average correlation coefficient of 0.9998 during validation. The R.S.D. ranged from 1.15 to $3.16 \%$ for inter-day samples and from 2.16 to $2.96 \%$ for intra-day samples. The limit of detection (LOD) for TMP was $10 \mathrm{ng} / \mathrm{mL}$ and the extraction efficiency amounted to over $90 \%$.

Pharmacokinetics and Statistical Analysis Pharmacokinetics (PK) parameters were estimated by non-compartmental analysis. The maximum plasma concentration $\left(C_{\max }\right)$, the minimum plasma concentration $\left(C_{\min }\right)$ and the time to reach maximum concentration $\left(T_{\max }\right)$ were determined by inspection of individual plasma concentration-time profiles. The area under the plasma concentration-time curves to the last quantified sample time point $\left(A U C_{0-t}\right)$ for TMP was calculated by the trapezoidal method. $A U C_{0-\infty}$ was determined by the sum of the $A U C_{0-t}$ plus the concentration at the last quantified time point divided by the estimated elimination rate constant, k. $A U C$ at steady-state $\left(A U C_{\mathrm{ss}}\right)$ was the $A U C$ from time 0 to $\tau$, where $\tau$ was the interval between administrations in the multiple-dose study ( $8 \mathrm{~h}$ for oral tablet and $24 \mathrm{~h}$ for the patch application). $M R T_{0-t}$ value was calculated by non-compartmental analysis. The average steady-state serum concentration $\left(C_{\mathrm{av}}\right)$ was calculated as the $A U C_{\mathrm{ss}} / \tau$ and the degree of fluctuation (DF) was assessed as $\left(C_{\max }-C_{\min }\right) / C_{\mathrm{av}} \times 100 \%$. The total body clearance $(C L)$ was calculated using this equation: $C L=$ dose $/ A U C_{0-\infty}$. The relative bioavailability was calculated as a ratio, expressed as a percentage of dose-correlated $A U C$ for the patch to oral tablets. Individual parameters were compared using two-sided $t$-tests (' $3 \mathrm{P} 87$ program provided by the Chinese Society of Mathematical Pharmacology').

\section{RESULTS}

Pharmacokinetics of Single-Dose Administration of TMPP Tablets and TMP Patch Eighteen subjects completed the single-dose clinical study. Two subjects (one from each group) withdrew for personal reasons at the beginning of the single-dose pharmacokinetic study. No adverse events were reported. The mean plasma concentration-time profiles of TMP following the single-dose application of TMP patch and oral tablets are shown in Fig. 2. The comparisons in pharmacokinetic non-compartmental parameters are depicted in Table 1. The two one-sided statistical tests indicated that all

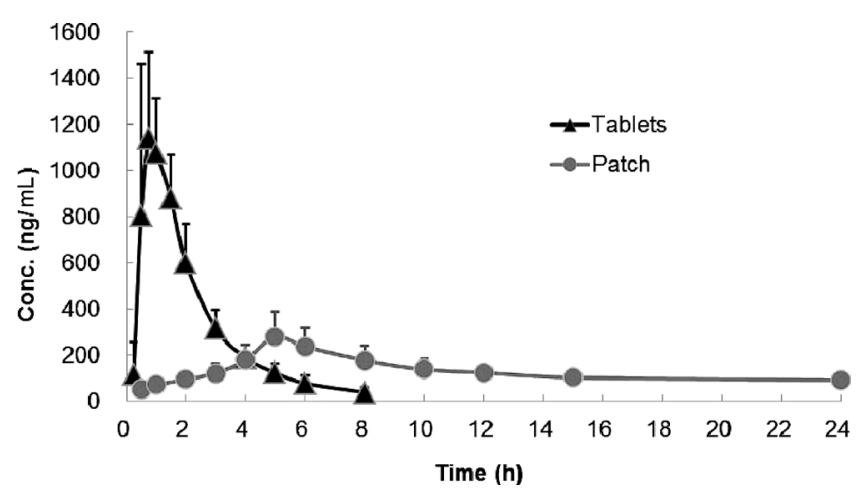

Fig. 2. Mean Plasma Concentration-Time Curve of TMP in Subjects after Single Administration of Patch (250 mg TMP) and Tablets (108mg TMP)

The standard deviation is represented by the error bar $(n=18)$.

Table 1. Non-compartmental Pharmacokinetic Parameters of Single Administration of Patch (250 mg TMP) and Tablets (108 mg TMP)

\begin{tabular}{ccc}
\hline \hline Parameters & Tablets & Patch \\
\hline$C_{\max }(\mathrm{ng} / \mathrm{mL})$ & $1284.26 \pm 367.05$ & $309.20 \pm 102.02 *$ \\
$T_{\max }(\mathrm{h})$ & $0.75(0.5-1.0)$ & $5(4-6)$ \\
$M R T_{0-t}(\mathrm{~h})$ & $2.31 \pm 0.44$ & $10.91 \pm 0.92 *$ \\
$A U C_{0-t}(\mathrm{ng} \cdot \mathrm{h} / \mathrm{mL})$ & $2634.4 \pm 530.5$ & $3114.90 \pm 514.10^{* *}$ \\
$A U C_{0-\infty}(\mathrm{ng} \cdot \mathrm{h} / \mathrm{mL})$ & $2715.6 \pm 542.3$ & $3313.58 \pm 506.17 * *$ \\
$F_{0-t}(\%)$ & & $53.90 \pm 15.32$ \\
$T_{1 / 2}(\mathrm{~h})$ & $1.49 \pm 0.32$ & \\
$C L / F(\mathrm{~L} / \mathrm{h})$ & $41.39 \pm 8.87$ & $42.96 \pm 16.78$ \\
\hline
\end{tabular}

Values represent mean \pm S.D. $(n=20) . * p<0.01 ; * * p<0.05$, compared to the corresponding parameters of the tablet.

the pharmacokinetic parameters were non-bioequivalence.

Following single-dose oral administration, plasma TMP concentrations increased rapidly, reaching mean peak plasma concentrations $(1284.26 \pm 367.05 \mathrm{ng} / \mathrm{mL})$ within $0.5-1 \mathrm{~h}$ (median time $0.75 \mathrm{~h}$ ) and declined rapidly below the limit of quantitation at $8 \mathrm{~h}$ post-dose. After a single-dose application of a patch, plasma TMP concentrations were measurable at $0.5 \mathrm{~h}$, showing there was nearly no time lag effect. Plasma concentrations then rose slowly to reach a peak plasma concentration of $309.20 \pm 102.02 \mathrm{ng} / \mathrm{mL}$ at $4-6 \mathrm{~h}$ (median time $5 \mathrm{~h}$ ); this was followed by a slow decline, but it maintained a level of $90 \pm$ $16.40 \mathrm{ng} / \mathrm{mL}$ until $24 \mathrm{~h} . M R T_{0-t}$ values were clearly prolonged: $10.91 \pm 0.92$ for TMP transdermally versus $2.31 \pm 0.44 \mathrm{~h}$ for TMP orally. The $A U C_{0-t}$ of $3114.90 \pm 514.10 \mathrm{ng} \cdot \mathrm{h} / \mathrm{mL}$ for the patch application was significantly greater than that of the oral administration $(2634.4 \pm 530.5 \mathrm{ng} \cdot \mathrm{h} / \mathrm{mL}), p<0.05$. After dose correction, the relative bioavailability of the patch was $53.88 \%$ compared with tablets.

Pharmacokinetics of Multiple-Dose Administration of TMPP Tablets and TMP Patch Twenty subjects completed the multiple-dose clinical study without any subjects withdrawing. No adverse events were reported, indicating good tolerability whether multiple-dose transdermal or oral administration. Table 2 shows the mean trough plasma concentrations following multiple-dose application of TMP patch and ingestion of tablets. The ANOVA analysis indicated that the trough plasma concentration after the $2 \mathrm{nd}$, 3rd, 4th, 5th day of patch application were not remarkably different $(p<0.05)$, 
Table 2. Mean Trough Plasma Concentration of TMP after Multiple-Dose Application of TMP Patch (250 mg TMP) and Tablets (54 mg TMP)

\begin{tabular}{crrrrr}
\hline \hline $\mathrm{ng} / \mathrm{mL}$ & \multicolumn{1}{c}{ 2nd day } & \multicolumn{1}{c}{ 3rd day } & 4th day & \multicolumn{1}{c}{ 5th day } & Average \\
\hline Tablets & $17.32 \pm 23.94$ & $15.55 \pm 22.89$ & $18.33 \pm 21.53$ & $14.67 \pm 22.27$ & $16.47 \pm 22.29$ \\
Patch & $128.45 \pm 23.09$ & $129.87 \pm 29.64$ & $141.97 \pm 35.64$ & $125.30 \pm 31.42$ & $131.40 \pm 30.38$ \\
\hline
\end{tabular}

Standard deviations are represented by the error bar $(n=20)$.

which suggests that steady state was reached after the second day of dosing. The total mean trough plasma level was $131.40 \pm 30.38 \mathrm{ng} / \mathrm{mL}$. Following multiple oral administration of $100 \mathrm{mg}$ TMPP tablets, nearly all the $C_{\text {min }}$ measurements were close to or below the limit of quantitation, showing that there was virtually no accumulation for the oral tablets.

The mean plasma concentration-time profiles of TMP following multiple-dose application of TMP patch and oral administration of tablets are shown in Fig. 3. The comparisons in non-compartmental pharmacokinetic parameters are depicted in Table 3. The two one-sided statistical tests indicated that all the pharmacokinetic parameters, other than the average plasma concentration, were non-bioequivalence.

The recommended dose of tablets (100 mg TMPP, $54 \mathrm{mg}$ TMP) were orally administered three times daily in the multiple-dose investigation. At steady-state TMP was rapidly absorbed and reached a $C_{\max }$ of $613.44 \pm 210.19 \mathrm{ng} / \mathrm{mL}$ at a median $t_{\max }$ of $0.75 \mathrm{~h}$ (range, $0.5-2.00 \mathrm{~h}$ ) and declined rapidly below the limit of quantitation at $8 \mathrm{~h}$ post-dose. Following multiple applications of the TMP patch, TMP plasma concentrations rose much more slowly and reached a mean peak plasma concentration $(326.13 \pm 114.42 \mathrm{ng} / \mathrm{mL})$ at a median $t_{\max }$ of $4 \mathrm{~h}$ (range, $3-8 \mathrm{~h}$ ) and then slowly declined, but still maintained a level of $125.30 \pm 31.42 \mathrm{ng} / \mathrm{mL}$ until $24 \mathrm{~h}$. MRT was prolonged from $2.09 \pm 0.46 \mathrm{~h}$ for oral tablets to $10.87 \pm 0.73 \mathrm{~h}$ for transdermal application. After the patch was removed it took $2 \mathrm{~h}$ for the plasma concentration to rapidly decline to below a quantitative level (data not shown), indicating that the slight reservoir effect in the skin was also sharply eliminated.

At steady state, the $C_{\max }$ of patch application was $53.2 \%$ lower than that of oral administration, and the $C_{\min }$ measurements were approximately $40.3 \%$ of $C_{\max }$. This was in contrast to oral dosing in which the concentrations fell from 613.44士 $210.19 \mathrm{ng} / \mathrm{mL}\left(C_{\max }\right)$ to nearly $0,8 \mathrm{~h}$ post-dose. The fluctuation degree of patch was $1.21 \pm 0.59$, which was smaller than that of the tablets $(4.02 \pm 1.12), p<0.001$. The relative difference between $C_{\max }$ and $C_{\min }$ plasma concentrations at $8 \mathrm{~h}$ for tablets and $24 \mathrm{~h}$ for patch was markedly lower with the patch when compared to tablets.

At steady state, the $A U C_{\mathrm{ss}}$ of a single dose of TMP tablets and patch was $1187.89 \pm 410.16 \mathrm{ng} \cdot \mathrm{h} / \mathrm{mL}$ and $3753.91 \pm$ $967.49 \mathrm{ng} \cdot \mathrm{h} / \mathrm{mL}$, respectively. Through dose-adjustment, the relative bioavailability of patch versus tablets was 72.84士 $32.98 \%$. The $A U C_{\mathrm{ss}}$ of a single dose of TMP tablets can be extrapolated to an $A U C_{\mathrm{ss}}$ of $3563.67 \mathrm{ng} \cdot \mathrm{h} / \mathrm{mL}$ if the same oral dose is given three times a day because there is nearly no accumulation at steady state; this was comparable to the $A U C_{\mathrm{ss}}$ of $3753.91 \pm 967.49 \mathrm{ng} \cdot \mathrm{h} / \mathrm{mL}$ for the once daily dosing of the transdermal patch. Also, TMP tablets and patch yielded similar average steady-state plasma concentration $C_{\mathrm{av}}(148.48 \pm$ $51.27,156.41 \pm 40.31 \mathrm{ng} / \mathrm{mL}$, respectively), $p>0.05$.

Comparative Single- and Multiple-Dose Pharmacokinetics of TMP Following Patch and Tablet Administration A loading dose of $200 \mathrm{mg}$ TMPP was used in the single dose

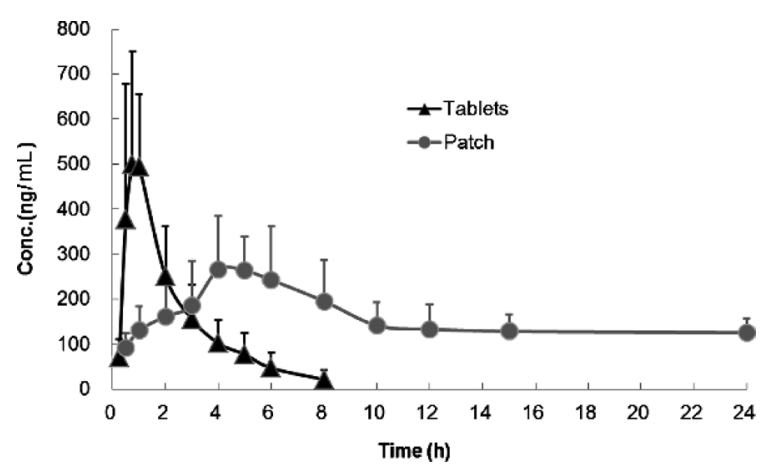

Fig. 3. Mean Plasma Concentration-Time Profile of TMP in Subjects after Last Dosing during $5 \mathrm{~d}$ of Administration of Patch (250 mg TMP) and Tablets (54 mg TMP)

The standard deviation is represented by the error bar $(n=20)$.

Table 3. Non-compartmental Pharmacokinetic Parameters of Multiple Administration of Patch (250 mg TMP) and Tablets (54 mg TMP)

\begin{tabular}{ccc}
\hline \hline Parameters & Tablets & Patch \\
\hline$C_{\max }(\mathrm{ng} / \mathrm{mL})$ & $613.44 \pm 210.19$ & $326.13 \pm 114.42^{*}$ \\
$C_{\min }(\mathrm{ng} / \mathrm{mL})$ & $16.47 \pm 22.29$ & $125.30 \pm 31.42^{*}$ \\
$C_{\mathrm{av}}(\mathrm{ng} / \mathrm{mL})$ & $148.48 \pm 51.27$ & $156.41 \pm 40.31$ \\
$T_{\max }(\mathrm{h})$ & $0.75(0.5-2.0)$ & $4(3-8)$ \\
$D F(\%)$ & $402.13 \pm 112.56$ & $121.32 \pm 59.19^{*}$ \\
$A U C_{\mathrm{ss}}(\mathrm{ng} \cdot \mathrm{h} / \mathrm{mL})$ & $1187.89 \pm 410.16$ & $3753.91 \pm 967.49^{*}$ \\
$F(\%)$ & & $72.84 \pm 32.98$ \\
$T_{1 / 2}(\mathrm{~h})$ & $1.61 \pm 0.41$ & \\
$M R T_{0-\tau}$ & $2.09 \pm 0.46$ & $10.87 \pm 0.73 *$ \\
\hline
\end{tabular}

Values represent mean \pm S.D. $(n=20) . * p<0.01$, compared to the corresponding parameters of the tablet.

investigation and the recommended dose of $100 \mathrm{mg}$ TMPP was used in the clinic for the multiple-dose pharmacokinetic studies. Single/multiple administration of TMPP tablets yielded a nearly identical biological half-life $(1.49 / 1.61 \mathrm{~h})$ and $C L / F$ $(41.39 / 46.50 \mathrm{~L} / \mathrm{h})$, which lie within previously reported respective ranges: $0.8-2.89 \mathrm{~h}$ and $15.36-66.36 \mathrm{~L} / \mathrm{h} .{ }^{8-10,24)}$ Based on dose and normalized body weight, the difference in $C_{\max }$ and $A U C$ between the single-dose and multiple-dose regimens were not significant, indicating that the pharmacokinetic characteristics is linear at the range $100-200 \mathrm{mg}$.

Following single and multiple-dose pharmacokinetic studies of TMP patch use, the $C_{\max }$ for the single and multiple dose regimens (309.19 versus $325.90 \mathrm{ng} / \mathrm{mL}$, respectively) did not differ significantly $(p>0.01)$. However, the exposure after multiple applications of patch $(3753.91 \mathrm{ng} \cdot \mathrm{h} / \mathrm{mL})$ was significantly higher $(13.3 \%, p<0.05)$ than that of single-dose application $(3313.58 \mathrm{ng} \cdot \mathrm{h} / \mathrm{mL})$. The corresponding relative bioavailability of $72.8 \%$ for multiple-dose patch applications was also significantly higher than $53.9 \%$ for single-dose patch application. Furthermore, $\mathrm{C}_{24}$ after the fifth application of the patch was $125.30 \mathrm{ng} / \mathrm{mL}, 1.35$ times higher than $\mathrm{C}_{24}(92.14 \mathrm{ng} / \mathrm{mL})$ after 
single-dose patch application $(p<0.05)$. These phenomena indicate that a small degree of drug accumulation may occur during multiple applications; this accumulation might be related to the slight and transient "reservoir effect" of drugs in human skin.

In-Vitro Permeation across Human Skin and in-Vivo Correlation The permeability profile of TMP permeated through human skin via TMP patch is presented in Fig. 4. The steady-state flux of TMP through human skin was 339.2 $17.4 \mu \mathrm{g} / \mathrm{cm}^{2} / \mathrm{h}$, exhibiting zero-order kinetics. TMP from the TDS patch showed a biphasic permeation profile, i.e. TMP permeated very rapidly over the first $12 \mathrm{~h}$; after that the permeation became slower.

The predicted steady state plasma level following application of the TDS patch was calculated as $163.90 \mathrm{ng} / \mathrm{mL}$. The predicted steady state plasma concentration of TMP in humans was calculated using the following equation:

$$
C_{\mathrm{ss}}=\frac{J_{\mathrm{ss}} \cdot A}{C L}
$$

where $C_{\mathrm{ss}}$ is the predicted steady plasma concentration (ng/ $\mathrm{mL}) ; J_{\mathrm{ss}}$ is the steady state flux $\left(339.2 \mu \mathrm{g} / \mathrm{cm}^{2} / \mathrm{h}\right) ; A$ is area of the applied patch $\left(20 \mathrm{~cm}^{2}\right) ; C L$ is the total body clearance (41.39 L/h from single-dose oral administration of tablets).

In the present study, the mean steady state plasma concentration following the application of the TDS patch in humans was $156.41 \pm 40.31 \mathrm{ng} / \mathrm{mL}$. The observed steady state plasma concentration of TMP was in close agreement with the predicted plasma concentration of TMP obtained from the invitro data.

\section{DISCUSSION}

Whether single or multiple-dose administration of TMPP tablets, the plasma TMP level rose sharply to $C_{\max }$ within $0.75 \mathrm{~h}$, and decline quickly with a biological half-life of approx. $1.5 \mathrm{~h}$. The phenomenon of rapid absorption and elimination is consistent with other reports about oral TMP administration. ${ }^{8-10,24)}$ On the contrary, following patch application, plasma TMP steadily rose to $C_{\max }$ at a $t_{\max }$ of $5 / 4 \mathrm{~h}$ (single/ multiple), and $M R T_{0-\tau}$ values were prolonged by 5.2 times for the patch versus tablets. This demonstrated that the TMP patch had a smoother concentration-time profile, which may result in more consistent efficacy compared with the oral tablets. Further, when the patch were used a significantly lower $C_{\max }$ and elevated $C_{\min }$ was observed at steady state and showed markedly fewer fluctuations, compared to the oral tablets. This suggests that potential side effects such as upset stomach, dry mouth and sleepiness that are reported with TMPP tablets might be greatly reduced if patches are used.

After single-dose application of the transdermal patch, TMP plasma concentrations reached a relatively sharp maximum at about $5 \mathrm{~h}$, in the range of $280 \mathrm{ng} / \mathrm{mL}$, followed by a slow decrease to below $100 \mathrm{ng} / \mathrm{mL}$ at $24 \mathrm{~h}$. In contrast, the permeation through human skin increased steadily until $24 \mathrm{~h}$, exhibiting zero-order kinetics, with a steady-state flux of $339.2 \mu \mathrm{g} / \mathrm{cm}^{2} / \mathrm{h}$. This contradictory phenomenon can be explained by the period flux at the sample time intervals. Transdermal flux rates for each time interval are shown in Fig. 5. These data were calculated from cumulative amounts that penetrated under in vitro conditions (depicted in Fig. 4). The transdermal flux

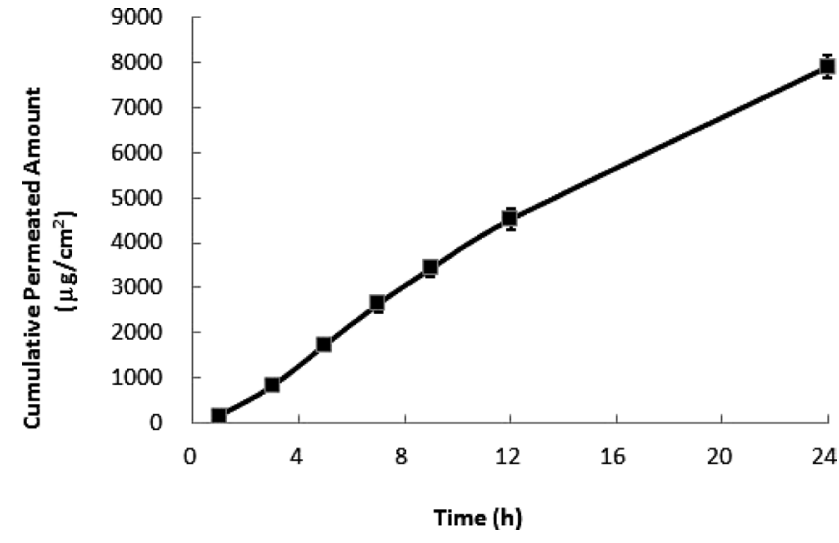

Fig. 4. The Mean Permeation Profile of TMP Permeated across Human Skin

The standard deviation between the four experiments is represented by the error bar.

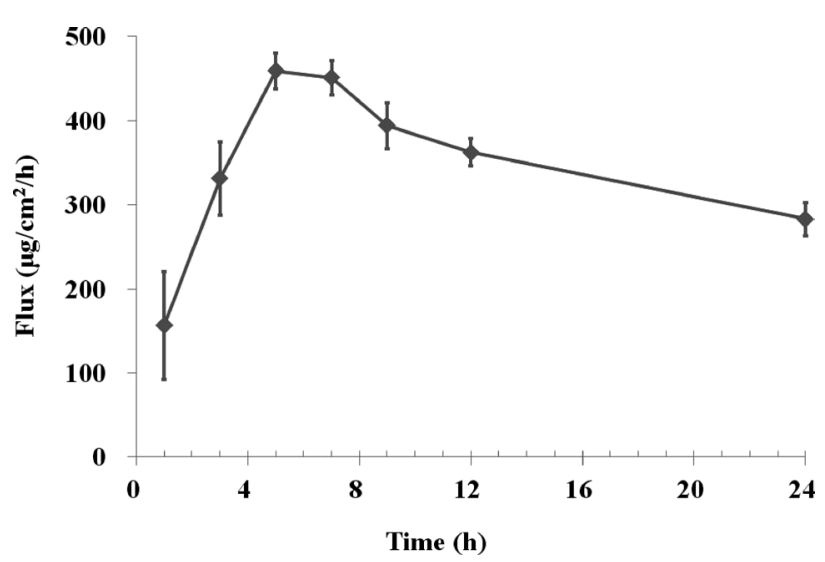

Fig. 5. The Period Flux of TMP Permeated through Human Skin at Each Sample Time

rate from the patch increased steadily, reaching a maximum value of $459 \mu \mathrm{g} / \mathrm{cm}^{2} / \mathrm{h}$ at 3 to $5 \mathrm{~h}$, and decreased slowly to a rate of about $283 \mu \mathrm{g} / \mathrm{cm}^{2} / \mathrm{h}$ from 12 to $24 \mathrm{~h}$. This phenomenon has also been observed in an Estradiol transdermal reservoir membrane system, which showed that the patients' $C_{\max }$ of Estradiol at $30 \mathrm{~h}$ corresponded with the maximum Estradiol flux through human skin at 20 to $30 \mathrm{~h}^{25)}$

In our previous formulation studies on TMP transdermal patch, eucalyptus oil was selected as the penetration enhancer because of superior efficacy when compared to azone and menthol. ${ }^{26)}$ Eucalyptus oil contains more than $80 \%$ cineole, a well-known skin penetration enhancer. Cineole enhances skin permeation by disrupting the inter-lamellar hydrogen-bonding network of the polar head group region in the stratum corneum bilayer, which facilitates the partition and permeation of small polar molecules through the skin. ${ }^{27,28)}$ Eucalyptus oil/ cineole has been shown to enhance the skin penetration of many drugs under in vitro conditions. ${ }^{29-32)}$ To our knowledge, this is the first time eucalyptus oil/cineole has been used in a human clinical trial. During our pharmacokinetic studies, no adverse events were reported and no signs of skin irritation/ sensitization were observed. This suggests that eucalyptus oil has a favourable safety and tolerability profile as a penetration enhancer in transdermal delivery systems.

To our knowledge, pharmacokinetic (PK) and pharmacodynamic (PD) studies of TMP have not been reported in either 
healthy volunteers or patients. PK-PD studies conducted in rats have shown that the concentrations of TMP in the effect compartment correlates with the observed pharmacological effect; for platelet aggregation rates the reported $t_{1 / 2}\left(K_{\mathrm{eo}}\right)$ and $\mathrm{EC}_{50}$ values are $1.044 \mathrm{~h}$ and $113.00 \mu \mathrm{g} / \mathrm{mL}$, respectively; for anti-hypertensive effects the reported $t_{1 / 2}\left(K_{\text {eo }}\right)$ and $\mathrm{EC}_{50}$ values are $0.167 \mathrm{~h}$ and $31.12 \mu \mathrm{g} / \mathrm{mL}$, respectively. ${ }^{33)}$ Taking species variation into account, after multiple-dose application of transdermal patch or tablets, the plasma concentration of $C_{\max }$ in humans may be at least two orders of magnitude below the $\mathrm{EC}_{50}$ in rats. However, the short $t_{1 / 2}\left(K_{\mathrm{eo}}\right)$ indicates that the plasma concentration of TMP has an intimate and positive relationship with its pharmacological effect. At steady state a $250 \mathrm{mg} / 20 \mathrm{~cm}^{2}$ TMP patch used once daily provided comparable exposure to $100 \mathrm{mg}$ TMPP tablets three times a day, and both administration routes had identical $C_{\mathrm{av}}$. We can reasonably conclude that a $250 \mathrm{mg} / 20 \mathrm{~cm}^{2}$ TMP patch used once daily could at least achieve a therapeutic effect comparable to oral $100 \mathrm{mg}$ TMPP tablets taken three times a day. Furthermore, transdermal dosing using patch may be more convenient and improve patient compliance, especially for those patients suffering angina pectoris or ischemic infarction, who often need long-term treatment.

\section{CONCLUSION}

The single- and multiple-dose pharmacokinetics studies demonstrated that the TMP patch can achieve a therapeutic effect that is comparable to oral administration. We also found that the TMP patch exhibited prolonged and sustained plasma levels, and exhibited fewer drug fluctuations, lower adverse effects, improved patient compliance, and is more convenient than oral administration. In-vitro permeation through human skin demonstrated zero-order kinetics with a flux of $364 \mu \mathrm{g} /$ $\mathrm{cm}^{2} / \mathrm{h}$. The predicted $C_{\mathrm{av}}$ was in excellent agreement with the observed $C_{\mathrm{av}}$. The favourable IVIVC substantiated the development of the TMP TDS patch.

Acknowledgment This work was supported by National Natural Science Foundation of China (81072594).

\section{REFERENCES}

1) Feng J, Li F, Zhao Y, Feng Y, Abe Y. Brain pharmacokinetics of tetramethylpyrazine after intranasal and intravenous administration in awake rats. Int. J. Pharm., 375, 55-60 (2009).

2) Tsai $\mathrm{TH}$, Liang C. Pharmacokinetics of tetramethylpyrazine in rat blood and brain using microdialysis. Int. J. Pharm., 216, 61-66 (2001).

3) Hintz KK, Ren J. Tetramethylpyrazine elicits disparate responses in cardiac contraction and intracellular $\mathrm{Ca}^{2+}$ transients in isolated adult rat ventricular myocytes. Vascul. Pharmacol., 40, 213-217 (2003).

4) Li M, Handa S, Ikeda Y, Goto S. Specific inhibiting characteristics of tetramethylpyrazine, one of the active ingredients of the Chinese herbal medicine 'Chuanxiong,' on platelet thrombus formation under high shear rates. Thromb. Res., 104, 15-28 (2001).

5) Sheu JR, Kan YC, Hung WC, Ko WC, Yen MH. Mechanisms involved in the antiplatelet activity of tetramethylpyrazine in human platelets. Thromb. Res., 88, 259-270 (1997).

6) Feng J, Liu RY, Wu GZ, Tang SB. Effects of tetramethylpyrazine on the release of PGI2 and TXA2 in the hypoxic isolated rat heart. Mol. Cell. Biochem., 167, 153-158 (1997).
7) $\mathrm{Xu} \mathrm{H}$, Shi DZ, Guan CY, Chen ZT. Clinical application and pharmacological actions of ligustrazine. Mol. Cell. Biochem., 23, 376-379 (2003).

8) Huang P, Li XH, Zhang H, Xiong YQ. Pharmacokinetics and bioequivalence of ligustazine phosphate pills in healthy volunteers. Chin. J. Clin. Pharmacol., 21, 445-448 (2005).

9) Cai W, Dong SN, Lou YQ. HPLC determination of tetramethylpyrazine in human serum and its pharmacokinetic parameters. Yao Хие Хие Bao, 24, 881-886 (1989).

10) Huang YZ, Chen C. Pharmacokinetics and bioequivalance of two preparations of ligustrazine phosphate in healthy volunteers. Herald Med., 28, 285-288 (2009).

11) Lou YQ, Zhang H, Cao X, Chen ML. The pharmacokinetics and disposition of tetramethylpyrazine phosphate in dogs and rats. Acta. Pharm. Sini., 21, 481-487 (1986).

12) Qi X, Liu RR, Sun D, Ackermann C, Hou H. Convolution method to predict drug concentration profiles of 2,3,5,6-tetramethylpyrazine following transdermal application. Int. J. Pharm., 259, 39-45 (2003).

13) Langer R. Transdermal drug delivery: past progress, current status, and future prospects. Adv. Drug Deliv. Rev., 56, 557-558 (2004).

14) Zhao JH, Ji L, Wang H, Chen ZQ, Zhang YT, Liu Y, Feng NP. Microemulsion-based novel transdermal delivery system of tetramethylpyrazine: preparation and evaluation in vitro and in vivo. Int. J. Nanomedicine, 6, 1611-1619 (2011).

15) Liu X, Liu H, Liu J, He Z, Ding C, Huang G, Zhou W, Zhou L. Preparation of a ligustrazine ethosome patch and its evaluation in vitro and in vivo. Int. J. Nanomedicine, 6, 241-247 (2011).

16) Liu X, Liu H, Zeng Z, Zhou W, Liu J, He Z. Pharmacokinetics of ligustrazine ethosome patch in rats and anti-myocardial ischemia and anti-ischemic reperfusion injury effect. Int. J. Nanomedicine, $\mathbf{6}$, 1391-1398 (2011).

17) Qiu L, Wang Q, Zhang J, Huo NB. Studies on inhibition of crystallization and in vitro percutaneous absorption of tetramethylpyrazine transdermal delivery system. Chin. Pharm. J., 41, 1642-1646 (2006).

18) Qi X, Ackermann C, Sun D, Liu R, Sheng M, Hou H. The prediction of plasma and brain levels of 2,3,5,6-tetramethylpyrazine following transdermal application. AAPS PharmSci, 4, 243-250 (2002).

19) Liu XQ, Lou YQ, Chen QT. The clinical pharmacokinetic studies of tetramethylpyrazine hydrochloride in normal volunteers and patients with acute cerebral ischemia disease. Zhongguo Lin Chuang Yao Li Xue Za Zhi, 7, 32-36 (1991).

20) Babu RJ, Pandit JK. Effect of penetration enhancers on the release and skin permeation of bupranolol from reservoir-type transdermal delivery systems. Int. J. Pharm., 288, 325-334 (2005).

21) Bian S, Doh HJ, Zheng J, Kim JS, Lee CH, Kim DD. In vitro evaluation of patch formulations for topical delivery of gentisic acid in rats. Eur. J. Pharm. Sci., 18, 141-147 (2003).

22) Weng WY, Xu HN, Li GX, Gao FY. HPLC determination of tetramethylprazine in serum and the permeation fluid. Journal of Shanghai Medica University, 379-380 (1997).

23) Weng WY, Shen T, Xu HN, Zhang JF, Huang JM, Huang ZC, Cai J. Determination of ligustrazine in human plasma by high performance liquid chromatography with solid-phase extraction. Chin. J. Chromatogr., 23, 276-278 (2005).

24) Zhu JX, Li JC, Zhu XG, Jiang ZW. Bioequivalence of ligustrazine phosphate dripping pills and tablets in healthy volunteers. Pharm. Care Res., 7, 268-270 (2007).

25) Rohr UD, Altenburger R, Kissel T. Pharmacokinetics of the transdermal reservoir membrane system delivering beta-estradiol: in vitro/in vivo-correlation. Pharm. Res., 15, 877-882 (1998).

26) Shen T, Xu HN, Weng WY, Zhang JF. Development of a reservoirtype transdermal delivery system containing eucalyptus oil for tetramethylpyrazine. Pharm. Res., 15, 877-882 (2013). 
27) Anjos JL, Neto DS, Alonso A. Effects of 1,8-cineole on the dynamics of lipids and proteins of stratum corneum. Int. J. Pharm., 345, 81-87 (2007).

28) Narishetty ST, Panchagnula R. Effect of L-menthol and 1,8-cineole on phase behavior and molecular organization of SC lipids and skin permeation of zidovudine. J. Control. Release, 102, 59-70 (2005).

29) El Maghraby GM. Transdermal delivery of hydrocortisone from eucalyptus oil microemulsion: effects of cosurfactants. Int. J. Pharm., 355, 285-292 (2008)

30) Biruss B, Kählig H, Valenta C. Evaluation of an eucalyptus oil containing topical drug delivery system for selected steroid hormones. Int. J. Pharm., 328, 142-151 (2007).
31) Das MK, Bhattacharya A, Ghosal SK. Effect of different terpenecontaining essential oils on percutaneous absorption of trazodone hydrochloride through mouse epidermis. Drug Deliv., 13, 425-431 (2006).

32) Narishetty ST, Panchagnula R. Transdermal delivery of zidovudine: effect of terpenes and their mechanism of action. J. Control. Release, 95, 367-379 (2004).

33) Liu XQ, Lou YQ, Shi WZ. Pharmacokinetic and pharmacodynamic correlation of tetramethylpyrazine and effect of liver function damage on its pharmacokinetics. J. Beijing Med. Univ. (Health Sciences), 1991, 185-187 (1991). 